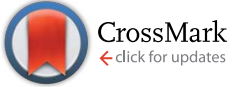

Cite this: RSC Adv., 2016, 6, 22090

Received 1st February 2016 Accepted 17th February 2016

DOI: 10.1039/c6ra03022j

www.rsc.org/advances

\section{Chitin-acetate/DMSO as a supramolecular green $\mathrm{CO}_{2}$-phile $\uparrow$}

\author{
Ala'a F. Eftaiha, ${ }^{a}$ Fatima Alsoubani, ${ }^{a}$ Khaleel I. Assaf, ${ }^{b}$ Werner M. Nau, ${ }^{b}$ Carsten Troll \\ and Abdussalam K. Qaroush*cd
}

The supramolecular chemisorption of $\mathrm{CO}_{2}$ by the oligomeric chitinacetate (CA) in DMSO as a green solvent offers a novel eco-friendly approach for $\mathrm{CO}_{2}$ capture. Since the amino groups in the sorbent material are blocked either by protonation or acetylation, the multiarmed hydroxyl based oligosaccharide captures $\mathrm{CO}_{2}$ through the formation of an organic carbonate species as confirmed by ${ }^{13} \mathrm{C} N M R$, in situ ATR-FTIR spectroscopy and conductivity. DFT calculations verified the formation of the $\mathrm{CA}-\mathrm{CO}_{2}$ adduct, in which the organic carbonate group is stabilized through supramolecular ionic interaction and hydrogen bonding with the neighboring ammonium ion and hydroxyl functional group along the oligomer backbone. The use of other polar aprotic solvents ( $\mathrm{N}, \mathrm{N}$-dimethylformamide (DMF), acetonitrile, and acetone) was not successful due to solubility issues.

\section{Introduction}

Since the early days of the twentieth century, the use of monoethanolamine (MEA) as a scrubbing agent for $\mathrm{CO}_{2}$ capturing has become a mature technology ${ }^{1}$ with known drawbacks upon regeneration, viz., cross-linking, evaporation, and limited recoverability. Several alternatives have been evaluated, ranging from solid sorbents (porous, non-porous) to different liquidbased candidates (chemi- or physisorption). ${ }^{2}$ Most materials act as nitrogen-bearing donors rather than oxygen-based sorbents due to the greater basicity of the former that can react chemically with $\mathrm{CO}_{2}$ following carbamate formation. ${ }^{3}$ From a practical industrial point of view, any competitive

${ }^{a}$ Department of Chemistry, The Hashemite University, P.O. Box 150459, Zarqa 13115, Jordan

${ }^{b}$ Department of Life Sciences and Chemistry, Jacobs University Bremen, Campus Ring 1, 28759 Bremen, Germany

'WACKER-Lehrstuhl für Makromolekulare Chemie, Technische Universität München, Lichtenbergstraße 4, 85747 Garching bei München, Germany. E-mail: abdussalam. qaroush@tum.de

${ }^{d}$ The Jordanian Pharmaceutical Manufacturing Company (JPM), P.O. Box 94, Naour 11710, Jordan

$\dagger$ Electronic supplementary information (ESI) available. See DOI: $10.1039 / \mathrm{c} 6 \mathrm{ra} 03022 \mathrm{j}$ technology needs to fulfil several critical parameters in terms of cost, eco-friendliness, recoverability, working temperature, efficiency of sorption and minimizing the use of sacrificial bases. One approach to increase the efficiency is the use of macromolecular, multi-reactive, and ideally bio-renewable materials to improve the stoichiometry of $\mathrm{CO}_{2}$ capture and reduce costs. ${ }^{4}$ Chitin and its hydrolyzed form, viz., chitosan, are potential candidates to replace MEA-based sorbents for $\mathrm{CO}_{2}$ capturing. What makes them appropriate as sorbents are their commercial availability, sustainability, mechanical strength and much more importantly is their nitrogen content. Solubility in common organic solvents and gelation are critical issues that hinder their mass use. Therefore, efforts are gathered to explore their $\mathrm{CO}_{2}$ capturing ability in ionic liquids (ILs). $)^{5,6}$

Away from ILs, we directed our focus towards the use of oligosaccharide rather than their corresponding parent polymers. A careful compromise between solubility, concentration, and prevention of gelation were taken into consideration by tailoring the degree of deacetylation (DDA). As a continuation of our research on green sorbents ${ }^{7}$ for the capture of $\mathrm{CO}_{2}$, we have discovered a simple method which utilizes chitin-acetate (CA, Scheme 1) as a scrubbing agent in green solvent, namely, DMSO, by-passing the use of ILs ${ }^{8-10}$ and/or superbases. ${ }^{11}$

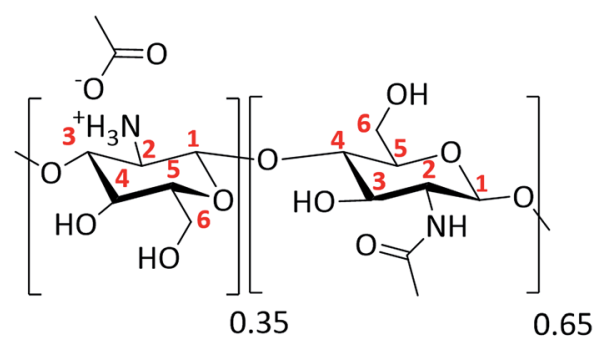

Chitin-acetate (CA)

Scheme 1 Structural representation for CA as deduced by nuclear magnetic resonance, elemental analysis and potentiometric titrations. 


\section{Results and discussion}

Two physical parameters regarding chitin and chitosan, viz., solubility and gelation (vide supra) are taken into consideration as a proper choice of a scrubbing material with reduced viscosity. ${ }^{\mathbf{1 2 , 1 3}}$ In fact, MEA solutions are always prepared with concentrations that are $20-40 \%$ (v/v) to diminish their corrosive character and increased viscosities upon capturing $\mathrm{CO}_{2}$. The search for scrubbing agents that can overcome such barriers, would be of great importance for both industrial and academic sectors. For the requested task, we were biased towards the use of low molecular weight chitin derivative as a green sorbent.

Fig. 1 shows partial ${ }^{13} \mathrm{C}$ NMR spectra before and after bubbling of $\mathrm{CO}_{2}$. A peak formed at $\mathbf{1 5 7 . 4} \mathrm{ppm}$ indicates the presence of carbonate ${ }^{\mathbf{1 1 , 1 4}}$ (no carbamate is formed as evidenced by ${ }^{13} \mathrm{C}$ NMR $) .{ }^{15}$ Precedent for chemisorption of $\mathrm{CO}_{2}$ through carbonate formation has been obtained by Stoddart and coworkers $^{\mathbf{1 4}}$ for cyclodextrins within extended metal-organic frameworks (MOFs). Herein, the choice of solvent proved to be critical. In particular, no reaction took place in aqueous solution. Presumably, the formation of the carbonate is facilitated in a polar aprotic solvent for kinetic (nucleophilicity) reasons. Herein, DMSO was used as a model solvent. The formation of carbonate at C-6 could be directly followed through the induced shift of the C- 6 peaks at $60 \mathrm{ppm}\left({ }^{13} \mathrm{C} \mathrm{NMR}\right.$, Fig. 1), in which a clear splitting was observed after the $\mathrm{CO}_{2}$ bubbling (there was no shift for C-2 before and after bubbling which confirms the absence of carbamates. C-2 peaks were 57.4 and $57.3 \mathrm{ppm}$, respectively).

To differentiate between carbamates and carbonates, in situ ATR-FTIR measurements were carried out in the presence of $\mathrm{CO}_{2}$ in DMSO as a green solvent. ${ }^{16}$ Fig. 2 supports the assumption of chemisorption via two major peak changes. On one hand, the appearance of a new peak assigned to $1555 \mathrm{~cm}^{-1}$ that can be ascribed to the vibrational mode of carbonate. ${ }^{17}$ On the other hand, the presumed formation of carbamates (if any) should be accompanied with the emergence of a newly formed peak centered at $c a .1690 \mathrm{~cm}^{-1}$ (absent in our case). ${ }^{18}$ The peak centered at $1610 \mathrm{~cm}^{-1}$ is assigned to a bending mode of amine, together with the stretching mode of amide (I) at $1675 \mathrm{~cm}^{-1}$ that is overshadowed upon capturing of $\mathrm{CO}_{2} \cdot{ }^{19}$ Further, the red shift

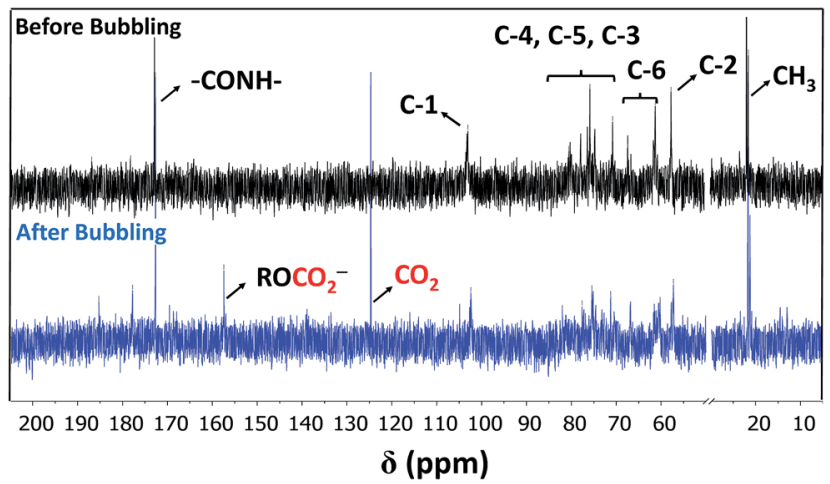

Fig. 1 Partial ${ }^{13} \mathrm{C}$ NMR spectra of CA dissolved in DMSO- $d_{6}$ obtained before (black) and after (blue) bubbling of $\mathrm{CO}_{2}$.

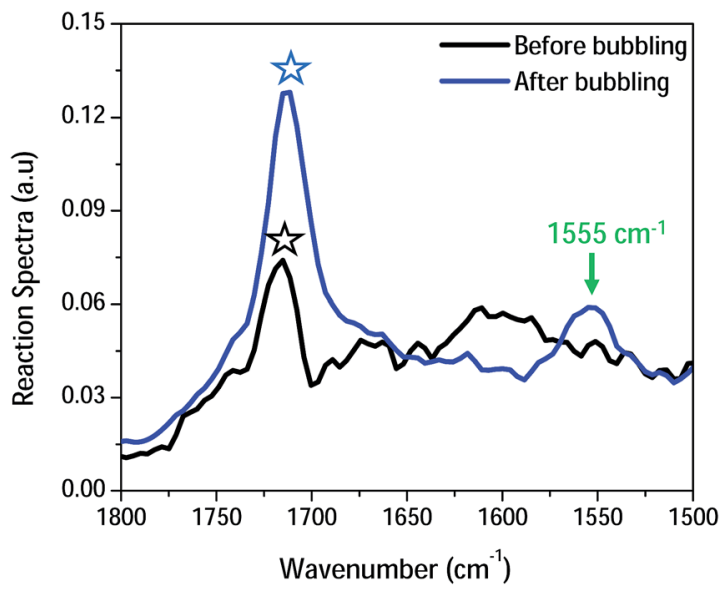

Fig. 2 Partial in situ IR spectra of CA $(10.0 \%(\mathrm{w} / \mathrm{v}))$ dissolved in DMSO obtained before (black) and after (blue) bubbling of $\mathrm{CO}_{2}$ ranging within $(1500-1800) \mathrm{cm}^{-1}$

in the $(\mathrm{C}=\mathrm{O})$ peak of acetate anion centered at $1720 \mathrm{~cm}^{-1}$ confirms the presumed interaction/metathesis of ammoniumacetate into ammonium-carbonate upon chemisorption of $\mathrm{CO}_{2} \cdot{ }^{18}$

A supramolecular stabilization of the organic carbonate species by ionic and hydrogen-bonding interactions of carbonate with neighbouring groups is presumed to be responsible for the observation that the formation of carbonates (-OH nucleophilic attack) was favoured over that of carbamates (amine nucleophilic attack). ${ }^{13} \mathrm{C}$ NMR indicated that upon capturing $\mathrm{CO}_{2}$, the addition of water to the $\mathrm{CA} /$ carbonate adduct showed that the system is a thermodynamically stable due to the persistence of the organic carbonate peak. In addition, a newly formed peak at about $166.2 \mathrm{ppm}$ indicated the formation of $\mathrm{HCO}_{3}{ }^{-}$because of interaction between physisorbed $\mathrm{CO}_{2}$ with water.

To prove the ion-pair formation in $\mathrm{CA} / \mathrm{CO}_{2}$ adduct, the electrical conductivity of CA dissolved in DMSO was measured as a function of $\mathrm{CO}_{2}$ bubbling time (Fig. 3). The dropdown in conductivity is explained by the formation of neutral ionic aggregates rather than the presence of individually solvated ions (ammonium and acetate). ${ }^{20}$ Doubling of the polymer concentration resulted in an increased conductivity keeping up the same trend. This is considered as another proof of concept for the chemisorption as reported by $\mathrm{Mu}$ and co-workers. ${ }^{6}$

This notion was supported by DFT-calculated structures of the presumed carbonates in a trimer model, which assumed a comparable alternating conformation as in the biopolymer. ${ }^{21}$ The obtained geometry afforded close interaction distances between carbonate-ammonium ions (1.52 $⿱$ ) and carbonatehydroxyl groups (1.66 ̊, Fig. 4).

The results obtained from the above-mentioned analyses (NMR, in situ IR and DFT calculations) are described in the reaction shown in Scheme 2. The usage of DMSO would activate the hydroxyl group at C- 6 of the amino pyranose ring toward nucleophilic attack, which result in chemisorption of $\mathrm{CO}_{2}$. The formed organic carbonate is stabilized via ionic interaction and 


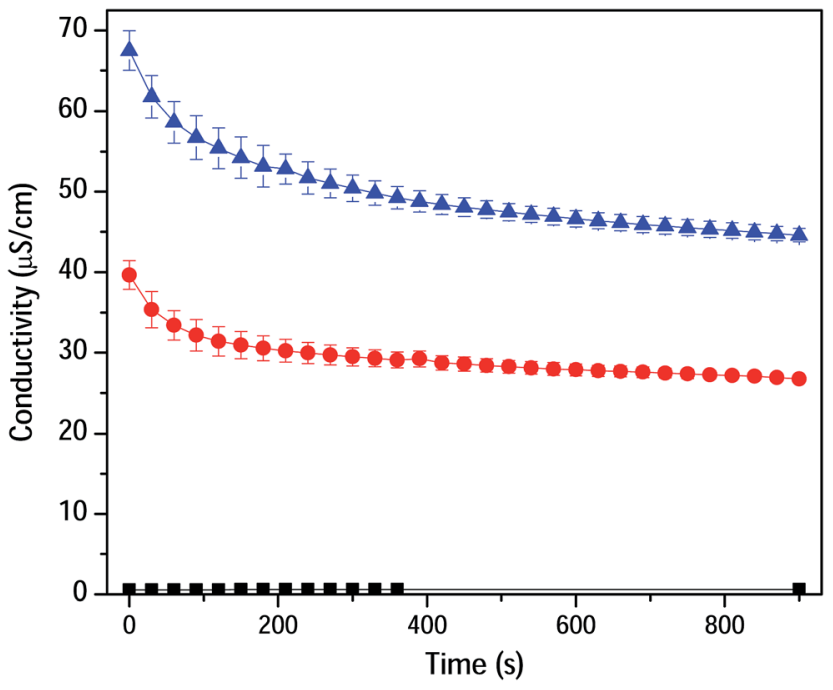

Fig. 3 Conductivity of CA dissolved in DMSO as a function of $\mathrm{CO}_{2}$ bubbling time. DMSO and CA solutions (0.33 and $0.67(\mathrm{w} / \mathrm{v}) \%)$ are shown in black, red and blue traces, respectively.

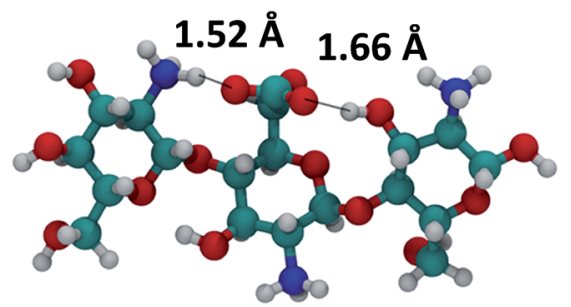

Fig. 4 DFT-optimized (B3LYP/6-31G*) geometry (gas phase) for a glucosammonium trimer as a model compound.

hydrogen bonding along the oligomer backbone. To our knowledge, activation of alcohols by DMSO is a first of its kind. We tried to carry out the bubbling experiment in other polar aprotic solvent such as acetonitrile, acetone and $N, N$-dimethylformamide (DMF). Unfortunately, the insolubility of CA (in the former two solvents) or the limited solubility (in DMF) prohibited further investigation of carbonate formation (see Fig. S1, (ESI $\dagger$ )). This implies that solubility, dielectric constant and $\mathrm{H}$-bond accepting character should be taken in consideration to carry out such reaction.
To measure the amount of sorbed $\mathrm{CO}_{2}$ by $\mathrm{CA}$ in DMSO volumetrically, pressurized vessels controlled with digital manometers were used. An arbitrary pressure was set at 4.0 bars to make sure it would remain in excess to achieve the equilibrated sorption capacities. The following conditions were adopted, namely $10.0 \%$ (w/v sorbent), $25.0{ }^{\circ} \mathrm{C}$, and $4.0 \mathrm{bar} \mathrm{CO}_{2}$. Gas sorption was measured relative to neat DMSO, which is known to absorb one bar of $\mathrm{CO}_{2}$ at the same conditions, and a value of $3.63 \mathrm{mmol}_{\mathrm{CO}_{2}} \mathrm{~g}_{\text {sorbent }}{ }^{-1}$ was determined for CA. This value is competitive to other scrubbing agents, ${ }^{2}$ which renders $\mathrm{CA}$ an interesting alternative from ecological and economic points of view. $\mathrm{CO}_{2}$ adsorption isotherm experiments at various pressure and temperature will be reported in an upcoming study to compare between the volumetric and gravimetric methods.

The reversibility of the process depends mainly on perturbing the supramolecular stabilized adduct. We tried several parameters e.g. $\mathrm{pH}$ change, sonication, thermal/electrical stimuli. Bubbles of $\mathrm{CO}_{2}$ were evolved upon applying the stress (vide supra). Therefore, the material is recyclable as an effective $\mathrm{CO}_{2}$ sorbent.

\section{Experimental}

\section{Materials and methods}

Unless otherwise stated, all chemicals were used without further purification. Chitin-acetate (CA) was made by G.T.C. Bio Corporation, Qingdao, China. For experimental manipulations, CA was dried in a vacuum oven at $50{ }^{\circ} \mathrm{C}$, overnight. Number average molecular weight $\left(M_{\mathrm{n}}\right)$ was determined to be $7 \mathrm{kDa}$, by multiangle light scattering (MALS) analysis using a Wyatt Dawn Heleos II in combination with a Wyatt Optilab rEX as concentration Source (Wyatt, USA). Based on $M_{\mathrm{n}}$ value, CA comprised of 15 units. $\mathrm{CO}_{2}$ (99.95\%, food grade) was purchased from advanced technical gases, Amman, Jordan. Dimethyl sulfoxide and DMSO- $d_{6}$ were purchased from M-TEDIA and SigmaAldrich, respectively. Solution ${ }^{13} \mathrm{C}-\mathrm{NMR}$ spectra were collected at room temperature using AVANCE-III $400 \mathrm{MHz}$ FT-NMR spectrometer NanoBay (Bruker, Switzerland) in either DMSO$d_{6}$ or $\mathrm{D}_{2} \mathrm{O}$. In situ IR measurements were carried out using a MMIR45m RB04-50 (Mettler-Toledo, Switzerland) with an MCT Detector, with silicon windows probe connected via pressure vessel; sampling 3500 to $650 \mathrm{~cm}^{-1}$ at 8 wavenumber

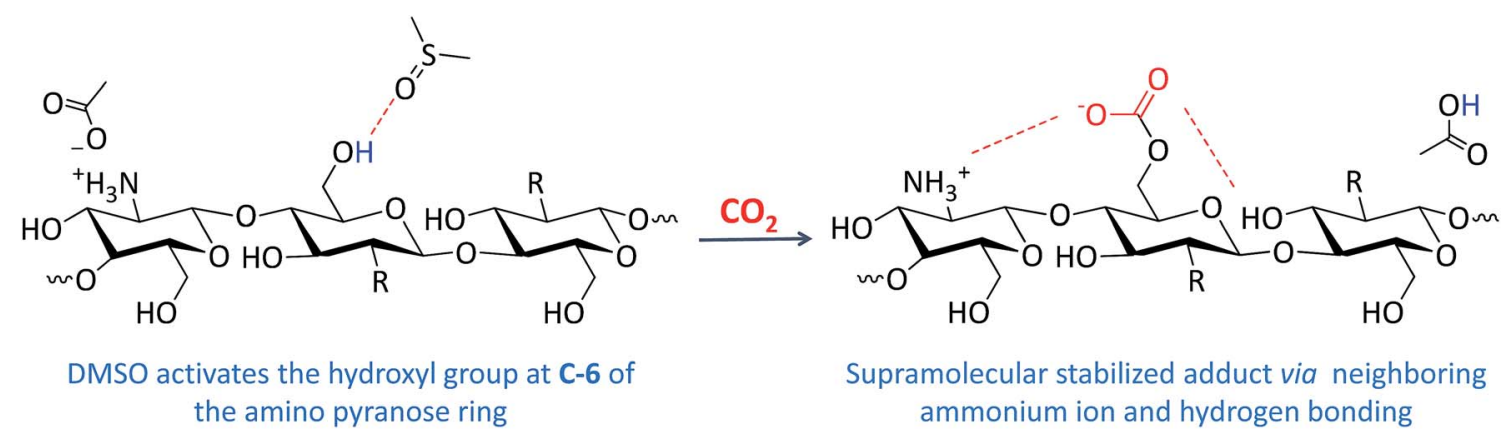

Scheme 2 The reaction of $\mathrm{CA}$ with $\mathrm{CO}_{2}$ in the presence of DMSO as a solvent; $\mathrm{R}=\mathrm{NH}_{3}{ }^{+}$or $\mathrm{NHCOCH}_{3}$. 
resolution; scan option: 64 ; gain: $1 \times$. Conductivity measurements were carried out using 712 Conductormeter (Metrohm, Switzerland). Calculations were performed within Gaussian 09. The full optimization was performed using DFT method (B3LYP/6-31G*). Minima were characterized by the absence of imaginary frequencies.

A. NMR manipulation ( $\mathrm{CO}_{2}$ bubbling). In an NMR tube, 30 $\mathrm{mg}$ of the substrate was dissolved in $0.5 \mathrm{~mL}$ DMSO- $d_{6}$. Upon dissolution, $\mathrm{CO}_{2}$ was bubbled into the NMR tube via a long cannula for 20 minutes. $\mathrm{CO}_{2}$ saturation was ensured using NMR spectroscopy.

B. In situ IR manipulation. In a $50 \mathrm{~mL}$ ATR-FTIR autoclave, $10 \%(w / v)$ CA was prepared using DMSO as a solvent. The autoclave was charged with 4.0 bars $\mathrm{CO}_{2}$ and left to scan for 4 hours (with a 15 seconds interval per scan). The initial and final drops in pressure were collected with a digital manometer. For control purposes, neat DMSO was charged under the same conditions.

C. Conductivity measurements. Conductivity was used to confirm the formation charged species upon bubbling $\mathrm{CO}_{2}$. A proper amount of CA was dissolved in DMSO using a $50 \mathrm{~mL}$ beaker to prepare 0.33 and $0.67 \%(\mathrm{w} / \mathrm{v})$. The conductivity was recorded every 30 seconds after bubbling $\mathrm{CO}_{2}$ using a conductor until no drastic changes took place.

\section{Conclusions}

In conclusion, we propose a new method to absorb atmospheric $\mathrm{CO}_{2}$ (without the use of stoichiometric amounts of the superbases or ionic liquids) in the presence of DMSO as a green solvent. Whether the $\mathrm{CO}_{2}$ chemisorption by carbonate formation is favored for kinetic reasons (higher nucleophilicity in polar aprotic solvents) or thermodynamic reasons (supramolecular stabilization of the carbonate by interaction with neighboring groups) requires further investigations. Regardless of the mechanistic details, the formation of stable adducts in the capture of $\mathrm{CO}_{2}$ by green sorbents is of considerable practical interest. The commercial availability of this oligosaccharide and cheap cost for its processing are additional assets. The use of other polar aprotic solvents ( $N, N$-dimethylformamide (DMF), acetonitrile, and acetone) was not successful due to solubility issues.

\section{Acknowledgements}

A. F. E. and A. K. Q. thank Dr Adnan A. Badwan, the CEO of the Jordanian Pharmaceutical Manufacturing Company (JPM), Naor, Jordan, for the generous gift of CA. Moreover, thanks are paid to Prof. Dr Adnan S. Abu-Surrah and Prof. Dr Hamzeh M. Abdel-Halim for providing access to their laboratory, HU, Zarqa, Jordan.

\section{References}

1 G. T. Rochelle, Science, 2009, 325, 1652-1654.

2 M. Pera-Titus, Chem. Rev., 2014, 114, 1413-1492.

3 S. Choi, J. H. Drese and C. W. Jones, ChemSusChem, 2009, 2, 796-854.

4 N. Yan and X. Chen, Nature, 2015, 524, 155-157.

5 H. Xie, S. Zhang and S. Li, Green Chem., 2006, 8, 630-633.

6 X. Sun, C. Huang, Z. Xue and T. Mu, Energy Fuels, 2015, 29, 1923-1930.

7 A. K. Qaroush, D. A. Castillo-Molina, C. Troll, M. A. AbuDaabes, H. M. Alsyouri, A. S. Abu-Surrah and B. Rieger, ChemSusChem, 2015, 8, 1618-1626.

8 L. A. Blanchard, D. Hancu, E. J. Beckman and J. F. Brennecke, Nature, 1999, 399, 28-29.

9 E. D. Bates, R. D. Mayton, I. Ntai and J. H. Davis, J. Am. Chem. Soc., 2002, 124, 926-927.

10 P. S. Barber, C. S. Griggs, G. Gurau, Z. Liu, S. Li, Z. Li, X. Lu, S. Zhang and R. D. Rogers, Angew. Chem., Int. Ed., 2013, 52, 12350-12353.

11 P. G. Jessop, D. J. Heldebrant, X. Li, C. A. Eckert and C. L. Liotta, Nature, 2005, 436, 1102.

12 K. Kurita, Mar. Biotechnol., 2006, 8, 203-226.

13 M. Rinaudo, Prog. Polym. Sci., 2006, 31, 603-632.

14 J. J. Gassensmith, H. Furukawa, R. A. Smaldone, R. S. Forgan, Y. Y. Botros, O. M. Yaghi and J. F. Stoddart, J. Am. Chem. Soc., 2011, 133, 15312-15315.

15 F. Barzagli, F. Mani and M. Peruzzini, Energy Environ. Sci., 2009, 2, 322-330.

16 US Environmental and Protection Agency, Dimethyl Sulfoxide Producers Association, Leesburg, VA, 2003.

17 S.-W. Song and S.-W. Baek, Electrochim. Acta, 2009, 54, 13121318.

18 B. E. Gurkan, J. C. de la Fuente, E. M. Mindrup, L. E. Ficke, B. F. Goodrich, E. A. Price, W. F. Schneider and J. F. Brennecke, J. Am. Chem. Soc., 2010, 132, 2116-2117.

19 D. Williams and I. Fleming, Spectroscopic methods in organic chemistry, McGraw-Hill, UK, 4th edn, 1989, Revised.

20 T. Köddermann, S. Klembt, D. Klasen, D. Paschek, U. Kragl and R. Ludwig, ChemPhysChem, 2012, 13, 1748-1752.

21 K. H. Gardner and J. Blackwell, Biopolymers, 1975, 14, 15811595. 